\title{
Nurses' Perception Of Leadership Styles, Job Satisfaction, And Contextual Performance
}

\section{SEFANUR SEYMEN ( $\nabla$ sefanurseymen@hotmail.com )}

Near East University

Aytolan YILDIRIM

Istanbul Universitesi

Research article

Keywords: Leadership, Leadership outcomes, Perception, Hospitals, Cyprus

Posted Date: March 10th, 2020

DOI: https://doi.org/10.21203/rs.3.rs-16636/v1

License: (9) This work is licensed under a Creative Commons Attribution 4.0 International License.

Read Full License 


\section{Abstract}

Background: This study, which is done using 606 nurses working in state hospitals under the Department Of Institutions For In-Patient Treatment Affiliated To Turkish Republic Of Northern Cyprus Ministry Of Health, aims to investigate the effect of manager-employee relationship on job satisfaction and contextual performance of perceived leadership style.

Methods: To determine the effect of leadership and job satisfaction on the contextual performance of the research, a screening model was used from descriptive research methods and a questionnaire consisting of four parts was prepared as data collection tool.

Results: Results show that age, gender, duration of work and working position were found to affect job satisfaction and contextual performance in general $(p<0,05)$.

Conclusions: This study concludes that personal profiles of nurses are essential determinants of how leadership, job satisfaction, and contextual performance is perceived.

\section{Background}

The concept of leadership emerged in academic field in early 19th century and especially quality management was attributed to research and education. In the field of health, literature is related to how the quality of health care results can be improved by leadership styles. Effective leadership includes ensuring extraordinary performance for ordinary people in terms of challenges and changes, constant performance and maintaining benefits. Leadership in health services is seen as an essential element for qualified health services, patient satisfaction and ensuring financial performance. Cummings et al. claimed that leadership practices in health institutions affects working environment, efficiency and the effectiveness of organization.

In recent years the knowledge which defines results of better patient as regards leadership and management is increasing. The increasing demand for health services requires nursing leaders to produce high quality performance with fewer resources. Nursing and especially professional application of their roles and the role of nurse managers at every stage of such application today have considerable importance as regards social health. Manager nurses assume essential responsibilities in directing the content of services within the framework of ethical rules of professional practices as well as the professionals in institutions. In order to perform these responsibilities in the most effective and efficient manner, they have to possess professional knowledge and skills as well as competence and qualification in using leadership characteristics. In order for the nurses who have effective role in health services to perform their tasks successfully, job satisfaction and contextual performance emerges as an important factor. In this framework, the article examines the impact of leadership behaviours of nurses with clinic responsibilities on their job satisfaction and contextual performance.

\section{Method}




\subsection{Model of the Research}

The study used scanning model which is a definitive research method in order to determine the impact of leadership and job satisfaction on contextual performance.

\subsection{Research Universe and Sample}

The research universe consists of 606 nurses working at public hospitals under the Boarding Treatment Institutions Office of Ministry of Health of Turkish Republic of Northern Cyprus. In this study, sampling was based on stratified and simple random sampling methods. The calculation formula of sample size whose universe is known was employed in calculating the size of the sample.

\subsection{Data Collection Tools}

A question form consisting of four sections was used as data collection tool in the study. The first section of the questionnaire consists of personal information, the second section consists of Minnesota Job Satisfaction Scale, the third section consists of Leadership Behaviours Description Questionnaire and the last section consists of Contextual Performance Scale.

\subsection{Collection of Data}

Following the preparation of questionnaire form, necessary permissions were obtained from Ministry of Health of Turkish Republic of Northern Cyprus and field application was performed based on face-to-face interview technique between July and October 2015. Prior to the application detailed information was given to the participants on the study and instructions were given on how to answer the questionnaire form.

\section{Findings}

Analysis shows that $88.72 \%$ of the nurses included in the research were females and $11.28 \%$ was males. $12.55 \%$ of the nurses was 30 years old and younger, $22.98 \%$ was between the ages of 31 and $35,127.23 \%$ was between the ages of 36 and $40,24.68 \%$ was between the ages of 41 and 45 , and $12.55 \%$ was older than 45 years of age. $84.47 \%$ of the participants was married and $15.53 \%$ was single. An examination of the distribution of participants as regards age groups shows that $48.51 \%$ has associate degree, $45.11 \%$ has undergraduate degree and $6.38 \%$ has graduate degree. $18.51 \%$ of the nurses stated that they their income level was low, $68.94 \%$ stated that their income level was medium and only $2.55 \%$ stated that their income level was high. $32.13 \%$ of the nurses who participated in the study had one child, $41.28 \%$ had two children and $4.47 \%$ had three and more children whereas $41.28 \%$ did not have any children. The results concerning professional features of the nurses were examined to show that $25.96 \%$ worked at a hospital for 10 years or less, $44.89 \%$ worked at a hospital for $11-20$ years and $29.15 \%$ worked at a hospital for more than 20 years. $27.45 \%$ of nurses work in their current department for 5 years or less, $26.17 \%$ for $6-$ 10 years, $20.43 \%$ for $11-15$ years, $10.64 \%$ for $16-20$ years and $15.32 \%$ for 21 years or more. $27.87 \%$ of nurses work only during daytime whereas $72.13 \%$ work on shifts. $95.74 \%$ of nurses are on the permanent 
staff. It has been found out that $2.77 \%$ of the nurses included in the study are chief nurses or deputy chief nurses, $9.79 \%$ are nurses in charge, $77.23 \%$ are service nurses and 10.21 are polyclinic nurses.

Within the scope of this study, it was found out that nurses received $3.40 \pm 0,54$ points from the entire Minnesota Job Satisfaction Scale. The lowest and highest average scores obtained by nurses from the scale are 1.80 and 4.95 , respectively. The average score obtained by nurses from the internal satisfaction sub-dimension of the scale is $3.51 \pm 0,55$ whereas the average score obtained from external satisfaction is $3,21 \pm 0,65$.

It has been observed that the nurses received $3.26 \pm 0,54$ points on average from the entire Leadership Behaviours Description Questionnaire with lowest and highest average scores of 1.31 and 4.65 , respectively. It has been seen that nurses received $3.80 \pm 0,52$ points from the entire Contextual Performance Scale with lowest and highest average scores of 2.42 and 5.00 respectively.

\section{Discussion}

Determination of the factors which will increase the job satisfaction and efficiency of nurses who are indispensable elements of health industry, offering regulations in order to create this result and identification of the managerial performance of nurse managers in order to ensure an increase in their performance is critical (Samadov, 2006). In our study, a general overview of satisfaction levels of nurses according to Minnesota job satisfaction scale, it can be seen that their job satisfaction is generally high $(3,40 \pm 0,54)$ and that internal satisfaction sub-dimension average score $(3,51 \pm 0,55)$ is higher compared to external satisfaction average score $(3,21 \pm 0,65)$. According to these results, it can be said that they reached higher satisfaction concerning the responsibility of the job, being successful and being appreciated, which are related to the qualification of the job, but they were less satisfied as regards working style, working conditions and hospital policy. Arslan (2012) studied the contextual performance level of nurses working at hospitals and related factors and concluded that general job satisfaction was at medium level and the internal satisfaction sub-dimension scores were higher compared to external satisfaction scores. Sezer (2015) looked into the job satisfaction of teachers and principals and identified that job satisfaction was at medium level. Another study conducted on haemodialysis nurses found out that job satisfaction of nurses was at medium level and that internal satisfaction was higher compared to external satisfaction. Kurt and Yiğit (2007) examined the Impact of Perceived Leadership Behaviours at Hospitals on the Job Satisfaction of Employees and claimed that professionals had medium level job satisfaction. Kim Brymer (2011) who studied the impact of ethical leadership on job satisfaction, commitment, behavioural results and company performance concluded that ethical leadership was positively related to the job satisfaction and contextual performance of medium level managers and that the job satisfaction of medium level managers was at neither low nor high. Kahraman et al. (2011) studied the job satisfaction of intensive care nurses and the factors that affect their satisfaction and found that the job satisfaction of nurses was at medium level. Keskin and Yildirim (2006) looked into the personal values and job satisfaction of nurses and found out that the average score of job satisfaction 
was at medium level. An evaluation of the information provided by the literature shows that nurses generally had medium to high level of job satisfaction, which is consistent with the findings of this study.

The nurses who participated in the study received $3.80 \pm 0,52$ points on average from the entire Contextual Performance Scale. Accordingly, students covered by the study answered "often" to the question on the entire contextual performance scale. Arslan (2012) stated that contextual performance was directly related to the leadership of the manager and found that the contextual performance of nurses was $3.87 \pm 0.59$. In addition, he found out that personal support sub-dimension $(4,10 \pm 0,56)$ was higher compared to organizational support sub-dimension $(3,60 \pm 0,60)$. Hetzler (2007) examined contextual performance longitudinally and concluded that motivation tendencies and the perception of team affected performance and that contextual performance was a stable uni-dimensional construct. Contextual performance indicators display the strength of performance in terms of awareness, consistency, extroversion, internal motivation orientation and perceived similarity. As a result of the study he conducted on undergraduate students, contextual performance score was determined as $5.82 \pm 0.69$. Beaty et al. (2001) studied the relation between personality and contextual performance on the basis of "strong" and "weak" personalities and found out that the contextual performance shown by weak and strong personalities in the face of identical cases was different and that average score of contextual performance was $5.2 \pm 1.1$ in general. Another study on the contextual performance of 300 nurses in Nigeria showed that there is high correlation between contextual performance and management style and that contextual performance increased as the respect increased (Mshellia et al., 2016).

Nurses included in the study received $3.26 \pm 0.54$ points on average from the entire Leadership Behaviours Description Questionnaire. Accordingly, nurses answered "usually" to the propositions in mobilizing the structure $(3.40 \pm 0,69)$ and communication sub-dimensions $(3.64 \pm 0,79)$ whereas they answered "sometimes" to the propositions in other sub-dimensions. The lowest and highest scores in leadership behaviours determination questionnaire was received in domination $(2.88 \pm 0,72)$ and organization $(3,31 \pm 0,68)$ sub-dimensions. Serinkan and İpekçi $(2005)$ conducted a study on leadership behaviours and eldership features of manager nurses and observed that the leadership behaviour with the highest frequency was risk-taking. Yilmaz and Bahçecik (2012) emphasised in their study on emotional intelligence skills and leadership behaviours of manager nurses and found out that the leadership behaviour questionnaire had $3.98 \pm 0.34$ points on average and that the highest scores were obtained from human-oriented leadership and transformative leadership sub-dimensions.

In our study, it has been found out that there is statistically significant difference between scores obtained from the entire Minnesota Job Satisfaction Scale $(p<0,05)$. It has bene observed that job satisfaction increased with age. However, there is no difference between genders. Sezer examined the job satisfaction of teachers and identified that job satisfaction increased with age and the biggest difference was between teachers at 22-35 age interval and 35-45 age interval; he also concluded that job satisfaction of teachers reached its maximum level after 45 years of age. There is not statistically significant difference between job satisfaction scores of females and males. A study on the individual and work-related factors in England as regards job satisfaction showed that there was significant 
difference between an individual at 20 years of age and another individual at 60 years of age and that job satisfaction increased as a person grew older (Gazioğlu and Tansel, 2002).

Another study which examined the impact of managerial communication skills on the level of job satisfaction and job commitment emphasised that job satisfaction was had strong correlation with age and job satisfaction increased with age (Paksoy et al., 2017). Özmutlu et al. (2013) studied the job satisfaction level of soccer referees and found out that job satisfaction level of 20 years old referees was around 20 whereas job satisfaction doubled for 45 years old referees. The findings of this study show similarity with the literature. In the first years of working life people are filled with high dreams and expectations. However, as time passes by, they become more realistic and disappointed with the realities of working life which do not come up to their expectations. Towards the end of their working life, job satisfaction increases as a result of more realistic expectations such as retirement and its benefits etc. (Türk 2007).

The scores received by nurses from organizational support sub-dimension of contextual performance scale shows statistically significant difference according to their age groups $(p<0,05)$. Nurses in $31-35$ age group received lower scores in this sub-dimension from the nurses in 36-40 age group and nurses above 46 years of age. The study conducted by Arslan (2012) on the relation between contextual performance and job satisfaction of nurses showed that young nurses had lower contextual performance scores compared to nurses at and above 30 years of age, which showed that organizational support subdimension score of nurses at and above 30 years of age was higher compared to nurses in 24-29 age group. Another study conducted on the relation between age and contextual performance stated that contextual performance was not considerably affected by age (Doğan, 2005). Trivellas et al. (2015) who studied the impact of career satisfaction on the job performance in accounting companies examined 84 persons and determined positive correlation between age and contextual performance. Kanigül (2009) examined contextual performance of hotel employees and concluded that organizational commitment increased with age.

It has been found out that there is statistically significant difference $(p<0,05)$ between the scores obtained by nurses from membership sub-dimension of Leadership Behaviours Determination Questionnaire whereas no significance was observed in other sub-dimensions. Nurses in 31-35 age group received lower scores form membership sub-dimension compared to nurses at and below 30 years of age. The study conducted by Çelik and Sümbül (2008) on Mersin province concerning education and gender factors in leadership perception concluded that gender and age factors were not effective on leadership perception. In their study on determination of the impact of leadership behaviours at hospitals on the job satisfaction of personnel, Tengilimioğlu and Yiğit (2005) detected no difference between age and gender in terms of leadership perception. Çağlar et al. (2005) evaluated the relation between personality characteristics of elementary school principals as perceived by teachers and their leadership characteristics and concluded that age and gender did not show any significant difference in terms of leadership perception. 
It has been found out that there is no statistically significant difference between scores obtained by nurses from the entire Minnesota Job Satisfaction Scale and the internal and external satisfaction subdimensions of the scale according to their number of children $(p>0,05)$. Several studies (Judge and Watabane, 1994, Pines, 2005) claim that number of children is very essential on job satisfaction and burnout because parents with children have more responsibilities and tasks and the rush and exhaustion in their private life affects their working life as a result of which their job satisfaction decreases. Uyguç et al. (1998) studied job satisfaction in relation to children and income and found out that people with small children had lower level of job satisfaction and that the job satisfaction of people without children or children above 18 years of age was higher. However, in our study no statistical relation was found between job satisfaction and number of children. Filiz (2014) examined the job satisfaction and burnout level of teachers and did not detect any relation between job satisfaction and number of children.

It has been concluded that there is no statistically significant difference between scores obtained by nurses from the entire contextual performance scale and personal support and organizational support sub-dimensions of the scale according to their number of children $(p>0,05)$. Hirlak et al. (2017) studied Kahramanmaraş case concerning the relation between emotional intelligence and job performance and some demographic features and found out that there is difference between people with children and people without children or single people as regards contextual performance and that the contextual performance of married people and people with children was higher. Another study conducted on nurses working at internal clinics found no relation between number of children and contextual performance which is parallel to our findings (Hirlak, 2016).

The scores obtained by nurses from the entire Leadership Behaviours Description Questionnaire are similar regardless of number of their children. Women with two children received higher scores from mobilizing the structure and integration sub-dimensions compared to other women. In addition, women with two children received higher scores from organization sub-dimension compared to women with no children and from production sub-dimension compared to women with single child. Yiğit (2000) examined nurses in charge of a clinic and expressed that leadership perception could increase with marriage or having children as it would increase responsibility. They expressed that these nurses could be more successful in terms of receiving obedience, dominating and motivating the structure compared to the nurses who do not have any children.

It has been found out that the difference between scores obtained from external satisfaction subdimension by nurses who participated in the study was statistically significant according to their history of working at hospitals and that external satisfaction sub-dimension increased although internal satisfaction did not change with history of working $(p<0,05)$. The study conducted by Yilmaz on the relation between leadership behaviour levels of elementary school principals and job satisfaction of teachers used a one-way analysis of variance for differences in job satisfaction scores based on service years and stated that there was no relation between working history and job satisfaction. Kurt and Yiğit (2017) studied the impact of leadership behaviours perceived at hospitals on the job satisfaction of employees and identified that the average dimension scores of working years was effective on job 
satisfaction and the participants with less than 21 years of working history had lower job satisfaction compared to nurses with fewer service years. In another study, it is found out that there is strong relation between seniority and job satisfaction of employees and as seniority increased so did job satisfaction (Iğdelipinar, 2013). Likewise, Oshagbemi (2000) examined the relation between seniority and job satisfaction and emphasized that job satisfaction was positively correlated with working history.

The conclusion reached as regards working history and job satisfaction shows that there is no significance in internal satisfaction but externa satisfaction increases with working history. However, studies in the literature display different results as regards the relation between working history and job satisfaction. Some researchers claim that job satisfaction decreases with working years whereas other emphasise increase. The most important reason for this variance could be that job satisfaction is considerably affected by professional differences (Laschinger et al., 2001). It is stated that seniority, which is generally called service term as well, has positive impact on the job satisfaction of employees and people who work in the same working environment for a long time develop increased commitment to the institution and higher job satisfaction. This result shows that employees who constitute the research group suffer from reduced job satisfaction as their retirement time approaches.

It has been determined that there is no statistically significant difference between scores obtained by nurses covered by the study from the entire contextual performance scale and its sub-dimensions according to their working history in the same department $(p>0,05)$. Kanigür (2009) stated that working history of hotel employees did not have any impact on their contextual performance. Aslan (2012) found out that the average contextual performance score of nurses who have been working at the same institution for 0-3 years was lower compared to the nurses who have been working at the same institution for 8 years and more. Dwaikat (2011) expressed that long-term working would increase salary and status as a result of which contextual performance of people could increase. However, Newby (2009) emphasised that long-term working could reduce contextual performance as it could lead to burnout.

There are contrasting results as to how contextual performance was affected by working terms. This can vary according to professional groups as well as income and status. This study did not detect any significance between working term and contextual performance. It has been found out that there is no statistically significant difference between scores obtained by the nurses from the entire leadership behaviours determination questionnaire and its sub-dimensions other than domination according to their service history in their current department $(p>0,05)$. It has been determined that there is statistically significant difference between scores obtained by nurses from dominating sub-dimension according to their working period and that nurses who have worked for 5 years or more in their current department received lower scores compared to other nurses from this sub-dimension $(p<0,05)$. As the working term in the institution increases, people get used to the institution and have control over several issues which can result in difference in leadership behaviours. Domination sub-dimension shows significance for especially people who have worked as manager in the same place. Yilmaz (2011) expressed that school managers with experience of less than 10 years and more than 30 years show differences in perception and definition of leadership. Çağlar et al. (2005) examined the relation between leadership patterns and 
job satisfaction of elementary school teachers and concluded that leadership behaviour score of people with more than 20 years of experience was higher.

Minnesota Job Satisfaction Scale of nurses who work only during daytime and who work on shifts. The scores obtained by nurses who work only during daytime was found to be significantly higher compared to nurses who work on shifts. Arslan (2015) studied leadership and job satisfaction in hospital management with a broad literature network and concluded that health professionals who continuously change shifts or perform night duty suffer from lower job satisfaction. The study conducted by Tengilimioğlu and Yiğit (2005) on hospital staff concluded that the job satisfaction of nurses and doctors working on night shifts is lower. Another study which examined the relation between leadership behaviours at service companies and job satisfaction indicated that working at night decreased job satisfaction (Tengilimioğlu, 2005). Aydin and Kutlu (2001) compared job satisfaction and working pattern of nurses and claimed that nurses who worked during daytime enjoyed higher job satisfaction compared to nurses who worked at night and with shifts. Another study found out that there is difference between job satisfaction of nurses depending on the variable of health care institution they work. In general, it has been found out that the job satisfaction of nurses with 21 years and more experience who work at special branch and hold lower, medium and higher polyclinic managerial positions and those who work only during daytime, only during weekdays and those who do not have any shifts enjoy higher job satisfaction (Cerit, 2009).

It has been found out that there is no statistically significant difference between scores obtained by nurses from the entire Contextual Performance Scale and its sub-dimensions $(p>0,05)$. Dwaikat $(2011)$ studied contextual performance of teachers and expressed that contextual performance of teachers working on a part-time basis is higher compared to full-time teachers. Another study which examined contextual performance of nurses reported that contextual performance of nurses working during daytime was higher compared to nurses working at night or on shifts (Aslan, 2012).

Erşan (1999) studied the relation between job satisfaction and job performance of nurses and stated that as the number and length of night duties increased, their contextual performance and job satisfaction decreased. Kahraman et al. (2011) evaluated the contextual performance of intensive care nurses and reported that the contextual performance of intensive care nurses could be lower compared to other nurses due to workload and working conditions. The performance at work is related to the extent to which employees feel themselves comfortable. As the workload of the employee decreases, contextual performance increases. However, in this study, it has been found out that working daytime only, working night time only or working on shifts does not have significance on contextual performance.

It has been found out that there is no statistically significant difference between the scores obtained by the nurses included in the study from the entire Leadership Behaviours Description Questionnaire and its domination, motivating the structure, membership, top-down communication, definition and production sub-dimensions according to their working pattern. Nurses who only work during daytime received higher scores from the entire scale as well as its domination, motivating the structure, membership, 
organisation, top-down communication, definition and production sub-dimensions compared to nurses who work on shifts. Uysal et al. (2002) examined the relations between leadership characteristics of hospital managers and work efficiency levels of employees and reported that doctors who work during daytime received higher scores from dominating the work, coordination and communication subdimensions.

It has been found out that there is statistically significant difference $(p<0,05)$ between scores obtained from the entire Minnesota Job Satisfaction scale and its sub-dimensions according to the positions of nurses. This difference is caused by the service nurses included in the study who received lower scores compared to other nurses from the entire scale and its internal satisfaction and external satisfaction subdimensions. Another study examined the job satisfaction level of health professionals according to their tasks and found out that technicians had the lowest job satisfaction whereas chief staff had the highest job satisfaction; nurses, midwives and health officials had lower job satisfaction than doctors (Tengilimioğlu, 2005). Aslan (2017) examined the relation between manager leadership styles and employee performance and concluded that the more comfortable working conditions an employee had, the higher his job satisfaction was; therefore, that this situation was directly related to their position.

It has been found out that there is statistically significant difference between the scores obtained by nurses from the entire Contextual Performance Scale and its personal support and organizational support sub-dimensions according to their positions $(p<0,05)$. Aslan (2012) found out that there is highly significant difference between contextual performance scores of nurses depending on the type of their roles and that the mean scores of special branch nurses and manager nurses had higher values in terms of both total scores and both sub-dimensions compared to service nurses. Another study which attempted to identify the contextual performance of directors, engineers, technicians and auxiliary service workers in defence industry determined that the contextual performance of directors was higher compared to engineers whose contextual performance scores were higher compared to technicians and auxiliary service workers (Batmaz, 2012).

It has been found out that there is statistically significant difference between the scores obtained by nurses from the entire Leadership Behaviours Description Questionnaire and domination, membership, top-down communication and production sub-dimension according to their positions $(p<0,05)$. It has been determined that the leadership behaviour scores of nurses in charge and chief nurses were higher. Yilmaz (2011) examined the leadership behaviour of teachers and found out that school principals and their deputies had higher leadership scores. There can be significant differences between leadership behaviours of managers and employees in the institution. For example, Koçak (2006) reported that leadership perceptions of school managers and teachers were very different from each other, that principals failed to convey the right messages to teachers with their leadership behaviours displayed at school, and caused diverse reactions from teachers.

It has been found out that there are statistically significant correlations between scores obtained by nurses from the entire Leadership Behaviours Determination Questionnaire and its sub-dimensions other 
than domination and the entire Minnesota Job Satisfaction Scale and its sub-dimensions $(p<0,05)$. These are positive and strong correlations and as the scores of Minnesota Job Satisfaction Scale increase so do the scores obtained from Leadership Behaviours Determination Questionnaire. Arslan (2017) examined transformative leadership, passive timid leadership and operation-based leadership types on job satisfaction and found out that job satisfaction of employees increased as the level of making their own decisions, being consulted and feeling comfortable increased and that especially transformative leadership improved job satisfaction of employees. Akyurt (2015) looked into the organisational commitment, job satisfaction and leadership styles of health professionals and reported that job satisfaction was highest with instrumental and interactive leadership. An examination of the literature shows that different leaders are effective in different professional group.

Minnesota Job Satisfaction Scale and Leadership Behaviours Description Questionnaire scores have statistically significant and positive impact on Contextual Performance Scale scores $(p<0,05)$. When Minnesota Job Satisfaction Scale score increases 1 unit, Contextual Performance Scale scores increase 0.19 times. When Leadership Behaviours Description Questionnaire score increases 1 unit, Contextual Performance Scale score increases 0.11 times. Another variable which affects job satisfaction is contextual performance as job satisfaction is a concept which is mostly related to the institution where the subject works. An increase in job satisfaction increases the benefit of the individual to the institution whose contextual performance improves. The reason for an employee to have high contextual performance in the institution is job satisfaction (Organ et al., 2006, Organ and Paine 1999). Although job satisfaction is a criterion for contextual performance, Organ and Ryan (1995) argue that there is also a positive correlation between organizational citizenship and job satisfaction. Harrison et al. (2006) examined 211 studies on job satisfaction and contextual performance and concluded that evidence which support the relation between job satisfaction and contextual performance is very strong and that positive and negative consequences of this situation will affect the institution mostly. From a different viewpoint, Edwards et al. (2008) concluded that performance depending on job satisfaction is affected more by performance-based job satisfaction.

Another study which examines the relation between job satisfaction and contextual (Van Scotter; 2000, Organ and Paine, 1999, Edwards and Bell, 2008) concluded that there is positive correlation between job satisfaction and performance and that contextual performance improved as job satisfaction increased.

\section{Conclusions}

This paper examines the impact of leadership styles perceived by nurses in their managers on job satisfaction and contextual performance. In the end of the study, it has been found out that they received $3.40 \pm 0.54$ points on average from the entire Minnesota Job Satisfaction Scale. It shows that the job satisfaction of nurses is generally high. They received $3.26 \pm 0.54$ points on average from the entire Leadership Behaviours Description Questionnaire and 3.80 \pm 0.52 points on average from the entire Contextual Performance Scale. No difference has been found between genders according to Minnesota Job Satisfaction Scale whereas female nurses received significantly higher scores than male nurses 
concerning contextual performance and leadership scales. It has been found out that age is more effective on job satisfaction and that job satisfaction increased as one grew older. The scores obtained by nurses working only during daytime from the entire Minnesota Job Satisfaction Scale and its subdimensions were found to be higher compared to nurses working on shifts. An evaluation on working style and leadership showed that nurses who work only during daytime received significantly higher scores from nurses who work on shifts from the entire scale and domination, motivating the structure, membership, organization, top-down communication, definition and production sub-dimensions. It has been found out that there is statistically significant difference between scores obtained from the entire Minnesota Job Satisfaction Scale and internal satisfaction sub-dimension of the scale. It has been determined that working history does not affect leadership and contextual performance but nurses with 5 years or less working experience in the same department received higher scores from job satisfaction scale compared to other nurses. It has been observed that working position is effective on job satisfaction, contextual performance and leadership. It has been found out that there are statistically significant correlations between scores obtained by nurses from the entire Leadership Behaviours Description Questionnaire and its sub-dimensions other than domination and the entire Minnesota Job Satisfaction Scale and its sub-dimensions $(p<0,05)$. Minnesota Job Satisfaction Scale and Leadership Behaviours Description Questionnaire scores have statistically significant and positive impact on Contextual Performance Scale scores $(p<0,05)$.

\section{Declarations}

\section{Abbreviations}

Not Applicable

\section{Ethics approval and consent to participate}

The study is a part of partial fulfillment of Ph.D. study, which was also approved by the Ministry of Health in the Turkish Republic of Northern Cyprus and Near East University. The survey informed participants that this study was entirely voluntary.

\section{Consent for publication}

Not Applicable.

\section{Competing interests}

We confirm that we don't have competing interests in publishing.

\section{Funding}

We received no funding for this study.

\section{Authors' contributions}


SS and AY designed the study. SS collected the data and performed the analysis. AY coordinated in writing the manuscript. All authors provided critical feedback and approved the final version of the manuscript.

\section{Acknowledgments}

The authors much appreciate help from Ministry of Health in North Cyprus.

\section{Availability of data and materials}

Not available.

\section{Authors' Contributions}

SS and AY designed the study. SS collected the data and performed the analysis. AY coordinated in writing the manuscript. All authors provided critical feedback and approved the final version of the manuscript.

\section{References}

Akyurt N. Alparslan M. Oktar F. Leadership styles in health professionals-job satisfaction-organizational loyalty model. Süleyman Demirel University Vizyoner Journal, Year: 2015, Vol: 6, Issue: 13, pp.50-61.

Arslan M. 2012. Contextual performance levels of nurses working at hospitals and related factors. İstanbul University Graduate School of Health Sciences, PhD Thesis. İstanbul.

Arslan B., Leadership and Job Satisfaction in Hospital Management. Beykent University, Graduate School of Social Sciences, 2015.

Aslan M. 2017. Relation between manager leadership styles and employee performance: application in a courier company. Beykent University Graduate School of Social Sciences

Aydin R., Kutlu Y. (2001) "Determination of variables related to job satisfaction of nurses and their interpersonal conflict tendencies and the relation of conflict tendency and job satisfaction", C.Ü. Nursing School Journal, 5(2), 36-45

Batmaz M. Impact of Management Styles of Managers on the Job Satisfaction of their Employees, Ufuk University Graduate School of Social Sciences, 2012.

Beaty J.C. Jr., Cleveland J.N., Murphy K.R. (2001) 'The Relation Between Personality and Contextual Performance in 'Strong' Versus 'Weak' Situations', Human Performance, 14(2), 125-148

Börü, D. and Güneşer, B. (2005), "Relation between leadership style and job satisfaction and the role of trust in leader", Hacettepe University Journal of Economic and Administrative Sciences, 23(1), 135-156. 
Cerit K. Factors which determine the job satisfaction of nurses: Organizational climate, sociodemographic and working characteristics. Dokuz eylül university Graduate school of health sciences, 2009.

Çağlar A., Yakut Ö.,Kkaradağ E., Personality Characteristics of Elementary School Teachers as Perceived by Teachers and an Evaluation of the Relation Between Their Leadership Behaviours. Ege Education Journal, 2005 (6) 1: 61-80

Çamlibel N.,Gül G., Bol P., Erbaycu AE. Comparison of Expected and Perceived Leadership Behaviours of Nurses (The case of an education and research hospital). Journal of Performance and Quality in Health, 2013. 6:1; 87-91.

Çelik C., Sünbül Ö., Education and Gender Factor in Leadership Perceptions: Study on Mersin Province. Süleyman Demirel University Journal of Economic and Administrative Sciences, 2008, C.13, S.3 s.49-66.

Doğan Y. (2005) 'A study in Kayseri on Determination of Positive and Negative Sensuality in Organizations on the Roles and Contextual Performance of Employees", Erciyes University Graduate School of Social Sciences, Unpublished MA Thesis.

Dwaikat M., Nazzal M. The effect of job satisfaction on the performance of nursing educators among nursing faculties in west bank. An-Najah National University Faculty of Nursing, 2011.

Edwards B.D., Bell S.T., Winfred A.J., Decuir A.D. (2008) 'Relationships Between Facets of Job Satisfaction and Task and Contextual Performance', Applied Psychology: An International Review, 57(3), 441-465

Erşan S. (1996) 'Job Satisfaction Level of Nurses and Factors that Affect Their Job Satisfaction Level', Cumhuriyet University, Graduate School of Health Sciences, MA Thesis, Sivas

Filiz Z. Examination of Job Satisfaction and Burnout Level of Teachers. International Management Economics and Business Journal, Bol. 10, Issue 23, 2014.

Gazioğlu Ş., Tansel A. Job Satisfaction in Britain: Individual and Job Related Factors. ERC Working Papers in Economics, 2002 03/03

Harrison D.A., Newman D.A., Roth P.L. (2006) 'How Important Are Job Attitudes? Meta-Analytic Comparisons of Integrative Behavioural Outcomes and Time Sequences', The Academy of Management Journal Archive, 49(2), 305-325

Hetzler JM. A Thesis Submitted to the Graduate Faculty of Auburn University. 2007. A longitudinal study of the predictors of contextual Performance

Hirlak B., Taşliyan N., Fidan E., Gül H. The relation of emotional intelligence with job performance and some demographic characteristics: an application in production industry in Kahramanmaraş. Kesit Akademi Dergisi (The Journal of Kesit Academy) Year: 3, Issue:9, September 2017, p. 108-130 
İğdelipinar N. The impact of ethical leadership behaviours of managers on the job satisfaction of employees, Bahçeşehir University, MA Thesis, 2013.

Judge, T.A. and S. Watanabe (1994), "Individual Differences in The Nature Of The Relationship Between Job And Life Satisfaction”, Journal Of Occupational And Organizational Psychology, 67, 101- 107.

Kara B. (2007) 'The relation between empathic tendencies and job satisfaction in haemodialysis nurses", Journal of Health and Society, 2, 14-18

Kanigür S. The impact of relation and task-oriented leadership perception of employees on performance: an application at four-star and five-star hotels in Ankara, Erciyes university graduate school of social sciences, 2009.

Kahraman G., Engin E., Dülgerler Ş., Öztürk E. (2011) 'Job satisfaction of intensive car enurses and factors that affect it', Dokuz Eylül University Nursing Vocaitonal School Electronic Journal, 4(1), 12-18

Keskin G., Yildirim G.Ö. (2006) 'Examination of personal values and job satisfaction of nurses', Ege University Journal of Nursing Vocational School, 22(1), 119-133

Koçak, T. (2006). The relation between transformative leadership styles of school managers and job satisfaction of teachers (the case of Ankara province) Gazi University, Ankara: Unpublished MA Thesis.

Kim WG., Brymer RA., The effects of ethical leadership on manager job satisfaction, commitment, behavioural outcomes, and firm performance. International Journal of Hospitality Management 30 (2011) $1020-1026$

Kurt S. Yiğit V. The impact of leadership behaviours perceived at hospitals on the job satisfaction of employees: an application at a university hospital. Süleyman Demirel University Graduate School of Social Sciences Journal Year: 2017/3, 28, p.107-131

Laschinger, H.K.S., Shamian, J., Thompson, D., (2001), "Impact of Magnet Hospital Characteristics on Nurses' perceptions of Trust, Burnout, Quality of Care, And Work Satisfaction", Nursing Economics, September-October, v.19, n.5, 209-219.

Mischellia PD. Emotional Intelligence and Contextual Performance Among Nursing Professionals In Jos Metropolis, Plateau State, Nigeria. Journal of Good Governance and Sustainable Development in Africa (JGGSDA), Vol. 3, No 1, April, 2016.

Newby Joe AE. (2009). Job Satisfaction Of Middle School Principals In Virginia.

Organ D.W., Podsakoff P.M., MacKenzie S.B. (2006) 'Organizational Citizenship Behavior, Its Nature, Antecedents and Consequences', Foundations Organizational Science, Sage Publications Inc., California, USA 
Organ D.W., Paine J.B. (1999) 'A New Kind of Performance for Industrial and Organizational Psychology: Recent Contributions to the Study of Organizational Citizenship Behaviour', International Review of Industrial and Organizational Psychology, 14, 337-368

Oshagbemi, T. (2000) "Is Length of Service Related to The Level Of Job Satisfaction?", International Journal Of Social Economics, 27 (3), Pp. 213-226.

Özmutlu I.., Tekin M., Yüksek S., Mutlu O., Erarslan M., An analysis on the job satisfactions levels of soccer referees. Turk J Sport Exe 2013; 15(1): 31-36

Paksoy M, Soyer F., Çalik F. The impact of managerial communication skills on the levels of job satisfaction and job commitment. Journal of Human Sciences, 14(1), 642-652.

doi:10.14687/jhs.v14i1.4259

Pines, A. M., \&Keinon, G. (2005). Stress and burnout: The significant difference. Personality and Individual Differences, 39, 625-635.

Samadov, S 2006, Job satisfaction and organisational commitment, an application in private sector. Unpublished MA Thesis, Dokuz Eylül University, Graduate School of Social Sciences, Izmir, Turkey.

Serinkan, C., İpekçi, i.(2005). A Research on Manager Nurses concerning Leadership Behaviours and Leadership Characteristics. Süleyman Demirel Faculty of Economic and Administrative Sciences Journal. 10 (1). 281-294

Sezer E. 2015. The relation between managing performance of elementary school principals as perceived by teachers and job satisfaction of teachers, MA Thesis, İstanbul Aydin University Graduate School of Social Sciences, İstanbul

Tanriverdi, H. and Safiye Paşaoğlu. (2014). "A Study on Pre-School Teachers on Determination of the Relatiosn between Transformative Leadership, Organisational Justice and Job Satisfaction." Electronic Social Sciences Journal 13(50), 274-293.

Tengilimoğlu, Dilaver. "A Study on Determination of the relation Between Leadership Behaviours and Job Satisfaction in Service Companies", G.Ü. Journal of Trade and Tourism Education Faculty, V. 1, 2005.

Tengilimoğlu, D. Yiğit, A.(2005). "A Field Study on Determination of the Impact of Leadership Behaviours at Hospitals on the Job Satisfaction of Personnel", Hacettepe Journal of Health Administration 8(3), 374400 .

Türk, MS 2007, Organizational Culture and Job Satisfaction (1. Edition) Ankara: Özkan Publications. Pp:82-102.

Uyguç N., Arbak Y., Duygulu E., Çiraklar N. Examination of the relation between job and life satisfaction under three basic assumptions. DEÜiïBF Journal Volume:13, issue:Il, Year:1998, pp:193-204 
Uysal, Ş.A., Keklik, B., Erdem, R. and Çelik, R. (2012), "The Examination of Relations Between Leadership Characteristics of Hospital Managers and Job Efficiency Levels of Employees", Hacettepe Journal of Health Administration,15(1), 25- 57.

Yilmaz BK, Bahçecik N. Emotional Intelligence Skills and Leadership Behaviours of Manager Nurses. i.Ü.F.N. Hem. Derg (2012) Volume 20 - Issue 2: 112-119

Yilmaz E.2016. The relation of nurses working at internal clinics with burnout level and emotional labour behaviour. Selçuk university graduate school of health sciences.

Yiğit R. Leadership behaviours of Clinic nurses in charge. C.Ü. Nursing Vocational School Journal, 2000, 4 (1)

Van Scotter J.R. (2000) 'Relationships of Task Performance and Contextual Performance With Turnover, Job Satisfaction and Affective Commitment', Human Resource Management Review, 10(1), 79-95.

\section{Appendix}

\section{Frequency Tables of Personal Information}

\begin{tabular}{|lllll|}
\hline Gender & & & & \\
\hline & Frequency & Percent & Valid Percent & Cumulative Percent \\
\hline Female & 417 & 88,7 & 88,7 & 88,7 \\
\hline Male & 53 & 11,3 & 11,3 & 100,0 \\
\hline Total & 470 & 100,0 & 100,0 & \\
\hline
\end{tabular}

\begin{tabular}{|lcccc|}
\hline Age Group & & & & \\
& Frequency & Percent & Valid Percent & Cumulative Percent \\
\hline At most 30 & 59 & 12,6 & 12,6 & 12,6 \\
\hline $31-35$ & 108 & 23,0 & 23,0 & 35,5 \\
\hline $36-40$ & 128 & 27,2 & 27,2 & 62,8 \\
\hline $41-45$ & 116 & 24,7 & 24,7 & 87,4 \\
\hline 46 and above & 59 & 12,6 & 12,6 & 100,0 \\
\hline Total & 470 & 100,0 & 100,0 & \\
\hline
\end{tabular}




\begin{tabular}{|lllll|}
\hline Marital Status & & & & \\
& Frequency & Percent & Valid Percent & Cumulative Percent \\
\hline Married & 397 & 84,5 & 84,5 & 84,5 \\
\hline Single & 73 & 15,5 & 15,5 & 100,0 \\
\hline Total & 470 & 100,0 & 100,0 & \\
\hline
\end{tabular}

\begin{tabular}{|lllll|}
\hline Education Level & & & & \\
& Frequency & Percent & Valid Percent & Cumulative Percent \\
\hline Vocational & 228 & 48,5 & 48,5 & 48,5 \\
\hline Bachelor & 212 & 45,1 & 45,1 & 93,6 \\
\hline Graduate & 30 & 6,4 & 6,4 & 100,0 \\
\hline Total & 470 & 100,0 & 100,0 & \\
\hline
\end{tabular}

\begin{tabular}{|ccccc|}
\hline Income Group & \multicolumn{3}{c|}{} \\
& Frequency & Percent & Valid Percent & Cumulative Percent \\
\hline Low & 87 & 18,5 & 18,5 & 18,5 \\
\hline Middle & 371 & 78,9 & 78,9 & 97,4 \\
\hline High & 12 & 2,6 & 2,6 & 100,0 \\
\hline Total & 470 & 100,0 & 100,0 & \\
\hline
\end{tabular}




\begin{tabular}{|lllll|}
\hline Hospital & & & & \\
\hline & Frequency & Percent & Valid Percent & Cumulative Percent \\
\hline Lefkoşa Burhan N. State Hosp. & 232 & 49,4 & 49,4 & 49,4 \\
\hline Gazimağusa State Hosp. & 135 & 28,7 & 28,7 & 78,1 \\
\hline Girne Akçiçek Hosp. & 51 & 10,9 & 10,9 & 88,9 \\
\hline Güzelyurt State Hosp. & 20 & 4,3 & 4,3 & 93,2 \\
\hline Barış State Hosp. & 32 & 6,8 & 6,8 & 100,0 \\
\hline Total & 470 & 100,0 & 100,0 & \\
\hline
\end{tabular}

\begin{tabular}{|lcccc|}
\hline Number of Children & \multicolumn{3}{l|}{} \\
& Frequency & Percent & Valid Percent & Cumulative Percent \\
\hline None & 104 & 22,1 & 22,1 & 22,1 \\
\hline One & 151 & 32,1 & 32,1 & 54,3 \\
\hline Two & 194 & 41,3 & 41,3 & 95,5 \\
\hline Three and above & 21 & 4,5 & 4,5 & 100,0 \\
\hline Total & 470 & 100,0 & 100,0 & \\
\hline
\end{tabular}

\begin{tabular}{|lcccc|}
\hline Frequency of Working & & & \\
& Frequency & Percent & Valid Percent & Cumulative Percent \\
\hline Daily & 131 & 27,9 & 27,9 & 27,9 \\
\hline Scheduled & 339 & 72,1 & 72,1 & 100,0 \\
\hline Total & 470 & 100,0 & 100,0 & \\
\hline
\end{tabular}




\begin{tabular}{|lllll|}
\hline Job Occupation & & & & \\
& Frequency & Percent & Valid Percent & Cumulative Percent \\
\hline Part time & 20 & 4,3 & 4,3 & 4,3 \\
\hline Full time & 450 & 95,7 & 95,7 & 100,0 \\
\hline Total & 470 & 100,0 & 100,0 & \\
\hline
\end{tabular}

\begin{tabular}{|lllll|}
\hline Job Position & & & & \\
\hline Frequency & Percent & Valid Percent & Cumulative Percent \\
\hline Head (nurse) & 13 & 2,8 & 2,8 & 2,8 \\
\hline Suthorized (nurse) & 46 & 9,8 & 9,8 & 12,6 \\
\hline Polyclinic Nurse & 48 & 77,2 & 77,2 & 89,8 \\
\hline Total & 363 & 10,2 & 10,2 & 100,0 \\
\hline
\end{tabular}

2. Meanscores and Descriptive Statistics of Questionnaire Instruments

\begin{tabular}{|lcccccc|}
\hline Descriptive Statistics & \multicolumn{1}{l|}{ Minimum } & Maximum & Mean & Std. Deviation \\
\hline Minnesota Job Satisfaction & 470 & 1,80 & 4,95 & 3,3907 &, 54485 \\
\hline Leadership Behaviour & 470 & 1,31 & 4,65 & 3,2583 &, 54023 \\
\hline Contextual Performance & 470 & 2,42 & 5,00 & 3,8065 &, 52618 \\
\hline & & & & & \\
\hline
\end{tabular}

\section{Correlation Matrix}




\section{Correlations}

\begin{tabular}{|c|c|c|c|c|}
\hline & & $\begin{array}{l}\text { Minnesota Job } \\
\text { Satisfaction }\end{array}$ & $\begin{array}{l}\text { Leadership } \\
\text { Behaviour }\end{array}$ & $\begin{array}{l}\text { Contextual } \\
\text { Performance }\end{array}$ \\
\hline \multirow{4}{*}{$\begin{array}{l}\text { Minnesota Job } \\
\text { Satisfaction }\end{array}$} & Pearson & 1 &, $214^{* *}$ &, $224^{* *}$ \\
\hline & Correlation & & & \\
\hline & Sig. (2-tailed) & &, 000 &, 000 \\
\hline & $\mathrm{N}$ & 470 & 470 & 470 \\
\hline \multirow[t]{3}{*}{ Leadership Behaviour } & $\begin{array}{l}\text { Pearson } \\
\text { Correlation }\end{array}$ &, $214^{* *}$ & 1 &, $157^{* *}$ \\
\hline & Sig. (2-tailed) & ,000 & & ,001 \\
\hline & $\mathrm{N}$ & 470 & 470 & 470 \\
\hline \multirow[t]{3}{*}{ Contextual Performance } & $\begin{array}{l}\text { Pearson } \\
\text { Correlation }\end{array}$ & $224^{* *}$ &, $157^{* *}$ & 1 \\
\hline & Sig. (2-tailed) & ,000 & ,001 & \\
\hline & $\mathrm{N}$ & 470 & 470 & 470 \\
\hline
\end{tabular}

**. Correlation is significant at the 0.01 level (2-tailed).

\section{Regression Analysis}

\begin{tabular}{|c|c|c|c|c|c|c|}
\hline \multicolumn{7}{|c|}{ Coefficients $^{\mathrm{a}}$} \\
\hline \multicolumn{2}{|c|}{ Model } & \multicolumn{2}{|c|}{ Unstandardized Coefficients } & \multirow{2}{*}{$\begin{array}{l}\text { Standardized Coefficients } \\
\text { Beta }\end{array}$} & \multirow[t]{2}{*}{$\mathrm{t}$} & \multirow[t]{2}{*}{ Sig. } \\
\hline & & $\mathrm{B}$ & Std. Error & & & \\
\hline \multirow[t]{3}{*}{1} & (Constant) & 2,790 & 187 & & 14,928 & 000 \\
\hline & Minnesota Job Satisfaction & 193 &, 044 & 200 & 4,363 & 000 \\
\hline & Leadership Behaviour & ,111 &, 045 & ,114 & 2,482 & 013 \\
\hline
\end{tabular}




\section{Model Summary}

$\begin{array}{lllll}\text { Model } & \mathrm{R} & \text { R Square } & \text { Adjusted R Square } & \text { Std. Error of the Estimate } \\ 1 & , 251^{\mathrm{a}} & , 063 & , 059 & , 51049\end{array}$

a. Predictors: (Constant), Leadership Behaviour, Minnesota Job Satisfaction

\begin{tabular}{|c|c|c|c|c|c|c|}
\hline \multicolumn{7}{|c|}{ ANOVA $^{\mathrm{a}}$} \\
\hline \multicolumn{2}{|c|}{ Model } & \multirow{2}{*}{$\begin{array}{l}\text { Sum of Squares } \\
8,149\end{array}$} & \multirow{2}{*}{$\begin{array}{l}\mathrm{df} \\
2\end{array}$} & \multirow{2}{*}{$\begin{array}{l}\text { Mean Square } \\
4,075\end{array}$} & \multirow{2}{*}{$\begin{array}{l}F \\
15,636\end{array}$} & \multirow{2}{*}{$\begin{array}{l}\text { Sig. } \\
, 000^{\mathrm{b}}\end{array}$} \\
\hline 1 & Regression & & & & & \\
\hline & Residual & 121,699 & 467 & ,261 & & \\
\hline & Total & 129,849 & 469 & & & \\
\hline \multicolumn{7}{|c|}{ a. Dependent Variable: Contextual Performance } \\
\hline
\end{tabular}

